\title{
FACTORES INFLUENTES NA APLICAÇÃO DA IAS 41 "AGRICULTURA" NAS EMPRESAS VITIVINÍCOLAS PORTUGUESAS
}

\author{
INFLUENTIAL FACTORS FOR THE APPLICATION OF IAS 41 \\ "AGRICULTURE" IN PORTUGUESE WINE COMPANIES
}

\section{FACTORES INFLUYENTES EN LA APLICACIÓN DE LA IAS 41 "AGRICULTURA" EN LAS EMPRESAS VITIVINÍCOLAS PORTUGUESAS}

\section{GRAÇA MARIA DO CARMO AZEVEDO}

Doutoramento em Gestão. Especialidade em Contabilidade concluído em 2006, no Instituto Superior de Ciências do Trabalho e da Empresa - ISCTE (com classificação de Aprovado com louvor e distinção). Mestrado em Contabilidade e Finanças Empresariais concluído em 2000, na Universidade Aberta / Instituto Superior de Contabilidade e Administração de Aveiro (com classificação de Muito Bom). Licenciatura em Auditoria Contabilística concluído em 1995, no Instituto Superior de Contabilidade e Administração de Aveiro (com média final de 14 valores). Professora Adjunta no Instituto Superior de Contabilidade e Administração da Universidade de Aveiro. Formadora (Oradora/Monitora) regular da Câmara dos Técnicos Oficiais de Contas (CTOC), ao abrigo do protocolo existente entre o ISCA-UA e a CTOC.Directora de Curso do Mestrado em Contabilidade. Directora de Curso do Mestrado em Contabilidade a Administração Pública. Directora do Centro de Estudos e Peritagem em Auditoria e Contabilidade (CEPAC). Técnica Oficial de Contas. Endereço: Instituto Superior de Contabilidade e Administração da Universidade de Aveiro, Rua Associação Humanitária dos Bombeiros de Aveiro, Apartado 58, 3811-902 Aveiro, Portugal.

Telefone: 919034813. E-mail: graca.azevedo@ua.pt

O artigo a seguir foi mantido em sua língua de origem.

RESUMO

A crescente importância dada ao justo valor como forma de mensuração, em detrimento do custo histórico, faz com que a determinação do valor, e posterior registo, esteja 
na agenda dos organismos de normalização. Nesse sentido, o International Accounting Standards Board (IASB) emitiu a International Accounting Standards (IAS) 41 na qual prevê a mensuração ao justo valor dos activos biológicos e produtos agrícolas.

Neste paper iremos abordar o sector vitivinícola português, por ser aquele que tem um peso mais significativo dentro da actividade agrícola e analisaremos a IAS 41 e o seu processo de desenvolvimento, focando a visão dos principais intervenientes no projecto de norma. Por fim, abordamos um estudo empírico efectuado com base em dados recolhidos através de inquérito às empresas com a Classificação Portuguesa das Actividades Económicas (CAE) 15931.

Em nível empírico, para percebermos quais os factores influentes na aplicação da norma, adoptamos as análises descritiva, factorial, de clusters e discriminante. Apesar das limitações da investigação, os resultados obtidos permitem concluir que os inquiridos deram mais relevância às variáveis relacionadas com a aplicabilidade da norma e com a experiência e o conhecimento desta e de outras normas, ou seja, consideraram a aplicabilidade da norma relevante para o sector.

Palavras-chave: Justo Valor; IAS 41; NCRF 17; Agricultura; Activos Biológicos. Classificação JEL: M41; M49.

\section{ABSTRACT}

The increasing relevance placed on fair value as a form of measurment, to the detriment of historical cost, places the determination of its value, and subsequent registry, on the agenda of the standardizing organizations. In this sense, the International Accounting Standards Board (IASB) issued the International Accounting Standards (IAS) 41, in which it provides for the measurement of the fair value of biological assets and agricultural goods.

In this paper we will broach the topic of the Portuguese wine industry, as it has a more significant role within the agricultural activity. We also analyzed IAS 41 and its development process, focussing our observations on the key players in the standard's draft. Lastly, we took on an empirical study which was conducted based on a questionnaire sent to a set of companies that are under the Portuguse Classification of Economic Activities (Classificação Portuguesa das Actividades Económicas - CAE 15931).

On an empirical level, in order to note which factors are influencing the standard's application, we adopted the descriptive, factorial, analysis of clusters and discriminants. Despite the limitations of the study, the obtained results allow one to conclude that those who were interviewed placed more relevance on the variables related to the applicability of the standard and, furthermore, on the experience and knowledge of this and other standards, which is to say, they consider the applicability of the standard relevant to the sector. 
Key Words: Fair Value; IAS 41; NCRF 17; Agriculture; Biological Assets.

JEL Classification: M41, M49.

\section{RESUMEN}

La creciente importancia dada al justo valor como forma de mensuración, en detrimento del coste histórico, hace que la determinación de su valor, y posterior registro, esté en la agenda de los organismos de normalización. En este sentido, el International Accounting Standards Board (IASB) emitió la International Accounting Standards (IAS) 41 en la cual prevé la mensuración al justo valor de los activos biológicos y productos agrícolas.

En este paper abordaremos el sector vitivinícola portugués, por ser aquél que tiene un peso más significativo dentro de la actividad agrícola y analizamos la IAS 41 y su proceso de desarrollo, enfocando la visión de los principales intervinientes en el proyecto de norma. Por fin, abordamos un estudio empírico efectuado con base en datos recogidos a través de investigación a las empresas con la Clasificación Portuguesa de las Actividades Económicas (CAE) 15931.

A nivel empírico, para que percibamos cuáles son los factores influyentes en la aplicación de la norma, adoptamos los análisis descriptivo, factorial, de clústeres y discriminante. A pesar de las limitaciones de la investigación, los resultados obtenidos permiten concluir que los inquiridos dieron más relevancia a las variables relacionadas con la aplicabilidad de la norma y asimismo, con la experiencia y el conocimiento de ésta y de otras normas, o sea, consideran la aplicabilidad de la norma relevante para el sector.

Palabras clave: Justo Valor; IAS 41; NCRF 17; Agricultura; Activos Biológicos. Clasificación JEL: M41, M49.

\section{INTRODUÇÃO}

A actividade agrícola tem características muito heterogéneas devido à grande diversidade de actividades que aglutina. A falta de normalização, a diversidade de actividades e a importância económica da actividade agrícola contribuem para o aumento das pressões existentes em dotar os utentes da informação financeira do sector com dados relevantes e fiáveis que lhes permitam conhecer a real posição financeira e efectuar a avaliação do desempenho das organizações.

A actividade agrícola é das actividades mais antigas e assume grande importância nas distintas economias. Tradicionalmente, associava-se um país com forte peso na actividade agrícola a um país subdesenvolvido, contudo, actualmente os países mais desenvolvidos têm investido no sector agrícola tornando-o cada vez mais forte. Como exemplo ilustrativo dessa situação verificamos que, em Portugal, a actividade agrícola represen- 
ta cerca de 2,5\% do valor acrescentado bruto em 2005 (OCDE, 2005), sendo a média dos países pertencentes à Organização para Cooperação e Desenvolvimento Económico (OCDE) de apenas 2,0\%. Interessa também referir que o Relatório das Perspectivas Agrícolas da OCDE e o da FAO (2007), para o período 2007-2016, preveem um crescimento favorável do Produto Interno Bruto (PIB) no seio dos países membros da OCDE, assumindo, em média, $2,5 \%$.

No contexto mundial, são poucos os países que têm normalização contabilística específica sobre agricultura, até porque essa actividade esteve sempre muito associada a explorações de pequena ou média dimensão com o único objectivo de obtenção do rendimento familiar. Contudo, durante os últimos anos, essa tendência foi contrariada e levou a uma maior procura de informação relativa ao sector, o que suscitou o interesse dos organismos de normalização contabilística no sector agrícola.

Nesse contexto, a União Europeia (UE) aprovou e emitiu o Regulamento 1606/2002 (CE, 2002) do Parlamento Europeu e do Conselho, a 19 de Julho de 2002, relativo à adopção das IAS como primeiro passo para a construção de um referencial contabilístico próprio conducente à harmonização na UE. Consequentemente, uma das normas adoptadas foi precisamente a IAS 41 - "Agricultura".

Também Portugal, por meio da Comissão de Normalização Contabilística (CNC), propõe um novo Sistema de Normalização Contabilística (SNC) no qual sugere um modelo baseado nas IAS, prevendo uma Norma específica para a agricultura, a Norma Contabilística e de Relato Financeiro (NCRF) 17 "Agricultura", que define o tratamento em termos de reconhecimento e mensuração dos produtos agrícolas.

A importância do tema e o interesse dos organismos reguladores nessa área nos últimos anos levaram-nos a efectuar este estudo com o objectivo de analisar algumas razões que suscitaram a elaboração da IAS 41 - "Agricultura" com preferência pelo justo valor em detrimento do custo histórico e a polémica subjacente ao projecto de norma, visto o projecto de norma ter sido muito polémico e existirem diferentes pontos de vista sobre esse tema.

$\mathrm{Na}$ execução deste trabalho analisamos os factores que podem levar as empresas a adoptar a IAS 41 voluntariamente, antes da obrigatoriedade de adopção da NCRF 17, recorrendo à análise factorial, de clusters e discriminante no sector vitivinícola, mais propriamente nas empresas com CAE 15931 - "Produção de Vinhos Comuns e Licorosos".

Depois de definida a metodologia do trabalho, apresentamos e analisamos os resultados obtidos através do inquérito realizado, no qual identificamos e sistetizamos os factores que influenciam a adopção da norma. Nesse sentido, verificamos que os inquiridos deram mais relevância às variáveis relacionadas com a aplicabilidade da norma e com a experiência e o conhecimento desta e de outras normas, considerando, assim, a aplicabilidade da norma relevante para o sector. 


\section{REVISÃO DA LITERATURA}

Foram diversas as tentativas de encontrar um modelo contabilístico para o sector, tanto em nível nacional como internacional, contudo, é no nível do IASB que surge o primeiro normativo internacional relevante e abrangente. A UE e mais tarde Portugal seguem os passos do IASB e também aprovam normas aplicáveis ao sector agrícola. Todo esse processo teve o seu desenvolvimento acelerado nos últimos anos:

- O IASB desenvolveu todo o processo da seguinte forma:

- Em 1996: Draft Statement of Principles (DSOP), nos quais eram enunciados os assuntos a normalizar, as formas de normalização e as alternativas para tal normalização.

- Em 1999: Exposure Draft E65, com a denominação de "Agricultura”, foi publicada em Julho de 1999 e submetida à apreciação dos utentes da informação financeira até 31 de Janeiro de 2000.

- Em 2000: International Accounting Standard 41 "Agriculture", aprovada em Dezembro de 2000 e com entrada em vigor para as demonstrações financeiras que comecem em ou após 1 de Janeiro de 2003.

- A UE aprova em 19 de julho de 2002 o Regulamento 1606/2002 do Parlamento Europeu e do Conselho, tendo como objectivo a adopção e a utilização das IAS por parte de algumas sociedades (com valores admitidos à negociação num mercado regulamentado pela UE), a partir de 1 de Janeiro de 2005. Dessa forma, Portugal também está abrangido por esse regulamento.

- Mais tarde, Portugal, através da CNC, emitiu o seu documento "Projecto de Linhas de Orientações para um Novo Modelo de Normalização Contabilística" (CNC, 2003). O documento final, aprovado em 13 de Julho através do DL158/2009, designado de SNC vem revogar o Plano Oficial de Contabilidade. O SNC prevê uma Norma específica para a agricultura, a NCRF 17 "Agricultura", que define as orientações para o tratamento das questões contabilísticas relacionadas com a agricultura, incluindo a mensuração ao justo valor.

\subsection{International Accounting Standard (IASB)}

O IASB desenvolveu todo o processo de normalização contabilística para a agricultura ao longo dos últimos anos através do DSOP, da Exposure Draft E65 e da International Accounting Standard $n^{\circ} 41$ "Agriculture".

O DSOP solicitou comentários sobre a viabilidade de desenvolvimento de uma Norma Internacional de Contabilidade sobre agricultura. A esse respeito as opiniões foram di- 


\section{repec}

vergentes, havendo quem defendesse que a diversidade da actividade agrícola não poderia ser tratada por uma única norma. Outros achavam que a norma a desenvolver deveria ser simples a adoptar, mas vasta na aplicação. Outros ainda acharam que deveriam estar associados princípios diferentes a actividades agrícolas com curtos e longos ciclos de produção. Também chamaram a atenção por esse sector ser em muitos países um dos principais sectores com significativo peso na economia de alguns países.

A Exposure Draft E65 denominada "Agricultura" foi publicada em julho de 1999 e submetida à apreciação dos utentes da informação financeira até 31 de janeiro de 2000, tendo se tornado muito polémica devido à não conformidade de opiniões dos diferentes utentes da informação financeira. A Exposure Draft (IASC, 1999) propõe em termos gerais que:

- Todos os activos biológicos sejam mensurados ao justo valor;

- Toda a produção agrícola no ponto de colheita seja mensurada ao justo valor; e

- O reconhecimento das alterações no justo valor de activos biológicos seja levado a gastos ou rendimentos.

Esse projecto de norma define como limite da sua área de intervenção o processo que culmina com a colheita, não sendo essa posição pacífica e havendo mesmo defensores de posições que incluíam alguns produtos obtidos após a colheita na actividade agrícola. Assim, foram vários os organismos que foram contra esse projecto de norma, tais como: $\mathrm{F}$ Hoffmann_La Roche (2000) da Suíça, IMA (2000) dos EUA, ACCA (2000) do Reino Unido, IACJCE (2000) de Espanha, AICPA (2000) da América etc.

O projecto de norma pôs à discussão pública várias questões que se tornaram muito polémicas devido à discordância de opinião entre os vários intervenientes. Apesar das questões postas em discussão estarem todas relacionadas com o nosso estudo, vamos aqui abordar apenas aquelas que se tornaram mais polémicas.

Relativamente à própria definição de justo valor, o projecto de norma (IASC, 1999) questiona que se existir mercado activo para activos biológicos à data da prestação de contas, o preço de mercado será a mensuração mais fiável para o justo valor desse activo inserido numa dada localização de venda ou uso. Da análise das respostas dos intervenientes a essa questão, verificamos que a maior parte concordou com o estabelecido no projecto de norma. Contudo, alguns intervenientes, tais como IAA (2000), Grupo G100 (2000), OROC (2000), CNDC e CNR (2000), SAICA (2000), ICPAK (2000), ACAG (2000), RJ (2000), Illovo Sugar (2000) e Abe (2000) consideraram que, por vezes, o preço em alguns mercados deveria ser ajustado para determinar o justo valor por terem em conta diversas situações em que os custos de pré-venda são muito relevantes e, por conseguinte, acreditarem que seria mais adequado deduzir esses custos do justo valor e utilizar preços de venda líquidos (em vez do justo valor) conforme descrito na IAS 36 - "Imparidade de activos". No que diz 


\section{repc}

respeito a essa questão, consideramos que, para o caso dos activos biológicos (videiras), o justo valor pode ser determinado com base no preço do mercado activo sempre que esteja inserido numa dada localização de venda ou uso.

Quanto à valorização dos activos biológicos, o projecto de norma (E65) previa que eles fossem valorizados ao justo valor à data do balanço, requeria também que os produtos agrícolas fossem mensurados ao justo valor no ponto da colheita. A maior parte dos intervenientes foram a favor do preconizado na E65, dos quais destacamos, dentre outros, o ICAZ (2000), a OROC (2000), a JICPA (2000) e a Deloitte Touche Tohmatsu (2000). Da opinião de que os activos biológicos deveriam ser valorizados ao custo até à colheita e os produtos agrícolas deveriam ser valorizados ao justo valor no ponto da colheita destacam-se, por exemplo, a FSIHC (2000), a EACP (2000) e a Nestlé (2000). Encontramos ainda defensores da valorização ao custo para todos os activos biológicos e produtos agrícolas, tais como, ICMAP (1999), FAR (2000), FIA (2000), IDW (2000), ICPAK (2000), EPK (2000), Sulzer (2000), Nutreco (2000) e Ernest \& Young (2000), por considerarem que os produtos agrícolas poderiam ser avaliados ao custo ou ao preço de mercado. Na nossa opinião, o justo valor é uma boa forma de valorizar todos os activos biológicos. No modelo de valorização assente no custo histórico, as alterações físicas ou de aumento das quantidades não têm reflexo apropriado nos resultados quando ocorrem. Consideramos que, para análise do desempenho de uma empresa, o justo valor fornece informação relevante para a tomada de decisões.

Outra questão de grande polémica foi o reconhecimento, no resultado líquido, das alterações do justo valor. A E65 sugere que os activos biológicos sejam valorizados ao justo valor e as alterações no justo valor dos activos biológicos sejam incluídas no resultado líquido, considerando mesmo esse julgamento como o mais relevante indicador do desempenho de uma empresa envolvida em actividades agrícolas. A maior parte dos intervenientes é a favor da divulgação das alterações do justo valor no resultado líquido do período. Destacamos, dentre os apoiantes dessa corrente, por exemplo, em Portugal, a OROC (2000). Contudo, fez uma restrição para as alterações da mensuração do justo valor no caso de rendimentos não realizados, os quais devem ser diferidos. Quer isso dizer que as alterações de valor não devem servir de medição do desempenho, a menos que os activos tenham sido vendidos. Posição contrária têm outros intervenientes, dos quais destacamos IAFEI (2000), grupo G100 (2000), EACP (2000), EPK (2000), ICPAK (2000), Ernst \& Young (2000), Sulzer (2000), Ascom (2000), Amen (2000) e Abe (2000) por considerarem que a divulgação das alterações do justo valor, deveria ser, na totalidade do capital, até o activo ser vendido ou consumido, data na qual são reconhecidas no resultado líquido desse período. Encontramos ainda um grupo de intervenientes, JICPA (2000), IIMC (2000), NBAA (2000), RJ (2000) e Deloitte Touche Tohmatsu (2000), a favor da divulgação das alterações de justo valor, na totalidade, no capital e até à colheita, data na qual seriam reconhecidas com equidade no resultado líquido do período. Somos da opinião de que as variações do justo valor 


\section{repc}

influenciam erradamente quer os indicadores de desempenho da empresa quer os sócios/ accionistas acerca do valor a distribuir como dividendos. Nesse sentido, consideramos que os resultados não realizados não devem ser distribuídos nem devem servir para aumentar o capital social da empresa.

Por sua vez, a IAS 41 tem como âmbito de normalização o tratamento contabilístico, a apresentação das demonstrações financeiras e os aspectos a divulgar nas actividades relacionadas com a agricultura, definindo como limite da sua área de intervenção o processo que culmina com a colheita. O IASB encoraja a sua aplicação antecipadamente, tendo a empresa que divulgar esse facto.

A norma estabelece como limite da sua área de intervenção - relacionado com a definição do tratamento contabilístico prescrito para o reconhecimento contabilístico dos activos biológicos (durante o seu período de crescimento, degeneração, produção e procriação) e mensuração inicial do produto agrícola (no momento da sua colheita) - o processo que culmina com a colheita (IASC, 2000: §4).

O objectivo da norma é o aperfeiçoamento e a harmonização dos métodos empregados para o reconhecimento, a valorização e o registo nos estados financeiros do impacto financeiro dos acontecimentos e transações associadas com a actividade agrícola.

Os activos biológicos são activos controlados por uma empresa como resultado de factos passados e dos quais se esperam benefícios económicos futuros (IASC, 1999: §36). A IAS 41 estabelece que sempre que o justo valor de um activo biológico possa ser mensurado com fiabilidade, a empresa deve mensurar no reconhecimento inicial e em cada data de balanço pelo seu justo valor menos custos estimados no ponto de venda (IASC, 2000: §12).

A IAS 41 define como justo valor (IASC, 2000: §8) a quantia pela qual um activo pode ser trocado ou um passivo liquidado entre entidades conhecedoras e dispostas a isso, numa transação ao alcance das mesmas, mas que nenhum relacionamento exista entre elas, isso é, actuando, cada uma, com independência. Mais uma vez verificamos a semelhança entre essa definição e as definições encontradas noutras normas.

No caso da agricultura, a determinação do justo valor poderá tornar-se mais simples se forem organizados grupos de activos biológicos ou produtos agrícolas com características similares, constituindo assim, características diferenciadoras aquando do estabelecimento do preço de mercado.

Os ganhos e perdas provenientes do reconhecimento inicial de um activo biológico ou produto agrícola pelo justo valor menos os custos estimados no ponto de venda devem ser incluídos na demonstração dos resultados no período contabilístico em que são gerados, assim como qualquer alteração do justo valor menos os custos estimados no ponto de venda de um activo biológico. 


\subsection{Regulamento $1606 / 2002 / C E$}

Com o objectivo da harmonização, surge o Regulamento $\mathrm{n}^{\circ}$. 1606/2002, do Parlamento Europeu e do Conselho, de 19 de Julho, que vem consagrar a aplicação na UE das IAS/IFRS, tendo como objectivo tornar obrigatória a apresentação e divulgação das contas anuais consolidadas das sociedades com valores mobiliários admitidos à negociação em mercados regulamentados, elaboradas segundo as Normas Internacionais de Contabilidade, para que os mercados financeiros funcionem de forma harmoniosa, eficaz e eficiente.

Esse Regulamento (CE, 2002: §5) prevê a possibilidade dos estados membros permitirem ou obrigarem o uso das Normas Internacionais de Contabilidade nas contas individuais. Cabe a cada estado membro reflectir sobre esse assunto, tendo em vista a tomada de posição pretendida.

Em face do exposto, Portugal não obrigou o uso das Normas Internacionais de Contabilidade nas contas individuais, mas elaborou, em 2003, o "Projecto de Linhas de Orientações para um Novo Modelo de Normalização Contabilística", que se baseia nas IAS/IFRS e foi aprovado em 2009 para entrar em vigor a partir de 1 de janeiro de 2010. Esse Projecto engloba uma norma específica para a agricultura designada de NCRF 17 "Agricultura".

\subsection{Norma Contabilistica de Relato Financeiro (NCRF) 17}

A NCRF 17 teve como suporte a IAS 41, tendo por base o aí estipulado. No entanto, e tendo em atenção alguns problemas já referenciados na discussão da Exposure Draft E65, somos a referir que a CNC teve em atenção alguns factores que abonam a favor da sua aplicação.

Assim, de acordo com o Decreto-Lei n. 158/2009, aceita -se a aplicação do modelo do justo valor na valorização dos activos biológicos consumíveis que não respeitem explorações silvícolas plurianuais, bem como nos produtos agrícolas colhidos de activos biológicos no momento da colheita. A NCRF 17 consta do Aviso n. ${ }^{\circ}$ 15655/2009 de 7 de Setembro.

Nesse sentido, é de referir que o SNC para o reconhecimento do justo valor, no que diz respeito à agricultura, subentende um valor de mercado, tendo optado pelo Sistema de Informação de Mercado Agrícola (SIMA).

O SIMA tem como objectivo o acompanhamento do mercado de produtos agrícolas, recolhendo os dados que permitam informar os decisores políticos, que têm a missão de acompanhar as políticas de mercado (nacionais ou comunitárias) e ainda informar o próprio mercado e os seus agentes, e prestando um serviço público de regulação (GPP, 2009). Ele presta informação sobre o preço de produtos agrícolas e análise de mercados agrícolas.

Assim, verificamos que a CNC está de alguma forma a colocar limites ao uso indisciplinado do justo valor. 


\section{repec}

\subsection{Estudos Desenvolvidos}

Dos estudos existentes sobre o tema em questão, destacamos o de Cairns et al. (2009) que teve como objectivo analisar se a alteração da mensuração para o justo valor levava a um aumento da comparabilidade nas empresas com valores admitidos à negociação na Austrália. Do estudo efectuado, os autores concluíram que os aumentos da comparabilidade no que diz respeito a activos biológicos e produtos agrícolas são insignificantes.

Fernandes (2009) analisou se a mensuração pelo justo valor responde eficazmente às especificidades da agricultura e se, em Portugal, os Técnicos Oficiais de Contas (TOC) conhecem o SNC e a IAS 41. Da análise concluiu que, embora considere o modelo do justo valor preconizado na IAS 41 e na NCRF 17 mais adequado do que o modelo do custo, a resposta dos TOC vai no sentido contrário. Todavia, considera que a tendência verificada não deve ser analisada isoladamente, pois também constactou que os TOC não conhecem adequadamente aquelas Normas nem estão ainda suficientemente preparados para enfrentar os desafios do novo paradigma do justo valor.

Peng e Bewley (2009) estudaram a adopção e implementação do justo valor dentro do contexto histórico da economia chinesa. Analisaram se a divergência de mesuração ao justo valor entre normativo local e IAS/IFRS é justificável e se poderia ser transposta num futuro próximo. Do estudo concluíram que a adopção das IAS na China aparece conduzida por condições políticas e económicas e não por auto-iniciativa. Consideram que existem dificuldades na implementação do justo valor e que a evolução da sua implementação tem sido lenta e pouco evoluiu desde a primeira tentativa, chamando a atenção para esforços futuros nesse sentido.

Por sua vez, Elad (2007) efectuou um estudo em que pretendia analisar o abandono do custo histórico e a consequente proliferação do uso do justo valor. Analisa o papel ideológico da IAS 41 em termos de conflito social nas indústrias de café e companhias florestais e considera que esse normativo fornece informação mais relevante, aliviando o conflito social.

Elad (2004) analisou o justo valor no sector agrícola e suas implicações para a harmonização internacional. Concluiu que seria praticamente impossível implementar o IAS 41 em países francófonos na ausência de uma revisão fundamental, se não o completo abandono, do "Plan Contable", visto existirem diferenças conceituais importantes entre as noções de rendimento, produção e valor acrescentado.

Tendo por base o estipulado na IAS 41, vamos proceder a um estudo empírico em que inquirimos as empresas de produção de vinhos comuns e licorosos, com o intuito de averiguar quais os factores previstos na IAS 41 que os incentivaria a aplicar a própria norma.

\section{ESTUDO EMPÍRICO}

Para analisarmos a influência de diferentes factores na adopção e utilização da IAS 41, procedemos à análise descritiva. De seguida, com o objectivo de reduzir a informação a ana- 
lisar, procedemos à análise factorial. Para concluir se as empresas que constituem a amostra apresentam algum grau de homogeneidade relativamente aos factores anteriormente identificados, recorremos à análise de clusters. Por fim, procedemos à análise discriminante com o objectivo exclusivo de validar a partição em clusters das empresas da amostra.

\subsection{Descrição da população em estudo e identificação da amostra}

O estudo baseia-se nas 288 empresas continentais com CAE 15931. Nesse universo incluem-se 33 empresas que não têm nenhuma pessoa ao serviço nem apresentam volume de negócios e por isso foram excluídas, ficando a população restringida a 255 empresas. Foram enviados inquéritos (Anexo) a todas as empresas que constituem o universo alvo. $A$ nossa amostra vai ser constituída pelas empresas que responderam ao referido inquérito, tendo esse número ascendido a 81 entidades, assumindo assim a forma de amostra por conveniência. Logo, a nossa amostra representa $32 \%$ do total da população. A repartição dessas sociedades segundo a sua natureza jurídica é a seguinte (Quadro 1):

\section{Quadro 1 - Forma Jurídica}

\begin{tabular}{|c|c|c|c|c|c|}
\hline \multirow{2}{*}{ Forma Jurídica } & \multicolumn{2}{|c|}{ Amostra (1) } & \multicolumn{2}{|c|}{ População (2) } & \multirow{2}{*}{$(1) /(2) \%$} \\
\hline & No Emp. & $\%$ & No Emp. & $\%$ & \\
\hline Sociedade Unipessoal & 2 & 2 & 2 & 1 & 100 \\
\hline Sociedade por quotas & 21 & 26 & 97 & 38 & 21 \\
\hline Sociedade Anónima & 22 & 27 & 48 & 19 & 45 \\
\hline Cooperativa de Responsabilidade Limitada & 36 & 44 & 108 & 42 & 33 \\
\hline Total & 81 & 100 & 255 & 100 & 32 \\
\hline
\end{tabular}

A forma jurídica que se apresenta sub-representada é a das sociedades por quotas, por representar $21 \%$ do total da população. No entanto consideramos que, em termos totais, a nossa amostra representa $32 \%$ do total da população, estando bem representadas, individualmente, cada uma das diferentes formas jurídicas.

O inquérito assumiu assim a forma de questionário com questões essencialmente fechadas. Nesse sentido, ele é constituído por escalas ordinais, tendo o respondente que escolher entre respostas alternativas fornecidas. Assim, em relação a cada uma das variáveis, foi solicitado a cada inquirido que indicasse numa escala de sete níveis de importância (1- nada importante,..., 7- muito importante) a influência exercida por cada variável relativamente à questão associada. As questões abertas têm conteúdo e forma livre de respostas, enquanto as questões fechadas têm opções reduzidas de resposta, apresentando categorias ou alternativas de respostas fixas (LESSARD-HÉBERT et al., 2005; BARROS; LEHFELD, 1986; HILL; HILL, 2002). 


\subsection{Metodologia}

Para facilitar a leitura e a construção dos quadros, decidimos abreviar o nome das nossas variáveis em cada um dos quadros no tratamento dos dados. De seguida, no Quadro 2, apresentamos uma tabela com as designações correspondentes.

\section{Quadro 2 - Designação das variáveis}

\begin{tabular}{|c|c|}
\hline Abreviaturas & Variáveis \\
\hline $\mathrm{X} 1$ & Conhecimento da IAS 41 \\
\hline $\mathrm{X} 2$ & Experiência na aplicação de outras IAS \\
\hline $\mathrm{X} 3$ & Facilidade de adaptação a mudanças \\
\hline $\mathrm{X} 4$ & Pertencerem a grupos internacionais \\
\hline X5 & Serem vistos como "exemplo" dentro do sector \\
\hline $\mathrm{X} 6$ & Existência de pessoal qualificado \\
\hline $\mathrm{X} 7$ & Os concorrentes já o terem feito \\
\hline $\mathrm{x} 8$ & Decisão da gestão \\
\hline X9 & Estarem teoricamente preparados \\
\hline X10 & Efectuarem reavaliações livres \\
\hline $\mathrm{X} 11$ & Efectuarem reavaliações legais \\
\hline $\mathrm{X} 12$ & Confiança na aplicabilidade da IAS \\
\hline $\mathrm{X} 13$ & Confiança nos resultados obtidos com aplicação da IAS \\
\hline $\mathrm{X} 14$ & Capacidade de mensurar fiavelmente o justo valor \\
\hline X15 & Melhorar os níveis de informação contabilística \\
\hline $\mathrm{X} 16$ & Concordância com o reconhecimento em perdas e ganhos dos ajustamentos do justo valor \\
\hline $\mathrm{X} 17$ & Concordância com a distinção entre activos biológicos consumíveis e de produção \\
\hline X18 & $\begin{array}{l}\text { Concordância com a distinção entre activos biológicos maduros ou adultos e imaturos } \\
\text { ou juvenis }\end{array}$ \\
\hline $\mathrm{X} 19$ & Concorda que a norma só seja aplicada aos produtos agrícolas no momento da colheita \\
\hline $\mathrm{X} 20$ & Concorda com a distinção entre subsídios governamentais condicionais e não condicionais \\
\hline $\mathrm{X} 21$ & Melhorar os níveis de informação para a gestão \\
\hline $\mathrm{X} 22$ & Melhorar a comparação entre as empresas do sector \\
\hline $\mathrm{x} 23$ & Serem pioneiros dentro do sector \\
\hline X24 & Acompanhamento das exigências contabilísticas \\
\hline $\mathrm{X} 25$ & Interesse pela inovação \\
\hline
\end{tabular}

Para analisarmos a influência dos diferentes factores na adopção e utilização da IAS 41, vamos proceder à análise descritiva, factorial, de clusters e discriminante. Na análise descritiva, calculámos os valores de tendência central e as medidas de dispersão, entre outras, como 
forma de caracterizar cada uma das sete razões gerais consideradas. De seguida, com as medidas de tendência ou localização central e medidas de dispersão, construímos a topologia das características mais frequentes apontadas como determinantes para o nosso objectivo.

A análise factorial permite-nos identificar um número relativamente pequeno de factores que podem ser usados para representar relações entre conjuntos de várias variáveis inter-relacionadas. Segundo Ferreira (2000, p. 91), a análise factorial tem como objectivo "descrever, se possível, as relações de covariância entre as várias variáveis em termos de um número reduzido de quantidades aleatórias subjacentes, mas não observáveis, chamadas factores."

No modelo de análise factorial, cada variável é expressa como uma combinação linear de factores que não são na realidade observados. Tem como objectivo simplificar as relações complexas que existam entre um grupo de variáveis, observadas através de factores comuns que fazem a ligação entre variáveis aparentemente independentes (JOHNS; LEE-ROSS, 1998).

A análise de clusters é uma técnica exploratória de análise multivariada que tem como objectivo o agrupamento de sujeitos ou variáveis com base nas suas características. Assim, os dados agrupados no mesmo cluster são muito semelhantes relativamente a qualquer critério de selecção predeterminado (HAIR et al., 1995; MAROCO, 2007; JOHNS; LEE-ROSS, 1998). Cada observação pertencente a um determinado cluster é similar a todas as outras pertencentes a esse cluster e é diferente das observações pertencentes aos demais clusters. Dessa forma, pretendemos com essa análise identificar grupos de respondentes que deram respostas semelhantes em duas ou mais variáveis, agrupando os factores já determinados num menor número de clusters com determinadas semelhanças.

A análise discriminante é uma técnica estatística multivariada que se aplica quando a variável dependente é qualitativa e as variáveis independentes são quantitativas. Tem como finalidade escolher as variáveis que distinguem os grupos, criando-se para isso funções discriminantes provenientes de combinações lineares das variáveis iniciais que maximizem as diferenças entre as médias dos grupos e simultaneamente minimizem a probabilidade de classificações incorrectas dos casos nos grupos (PESTANA; GAGEIRO, 2008). Utilizamos a análise discriminante com o único objectivo de determinar as variáveis que se discriminam entre os grupos, por meio da análise de variância univariada, validando assim a análise de cluster e confirmando os dados da análise factorial.

\subsection{Resultados Empíricos}

\subsubsection{Análise Descritiva}

Começamos por analisar as medidas de tendência central e verificamos que não se afastam muito umas das outras. Considerámos os valores da tendência central para hie- 
rarquizar as diferentes variáveis em termos de importância, condicionadoras de maior ou menor peso na adopção da IAS 41 "Agricultura". Para isso utilizamos a média, a moda e a mediana que registam o valor em torno do qual se tendem a agrupar as observações. No Quadro 3, apresentamos as medidas de tendência central a utilizar para a hierarquização por níveis de importância das diferentes variáveis:

Quadro 3 - Hierarquização das variáveis em função das medidas de localização central

\begin{tabular}{|c|c|c|c|c|}
\hline \multicolumn{2}{|c|}{ Abreviaturas } & Média & Mediana & Moda \\
\hline \multirow{11}{*}{ Nível 1} & $\times 14$ & 5,52 & 6,00 & 6 \\
\hline & $\mathrm{X} 8$ & 5,40 & 5,00 & 5 \\
\hline & $\mathrm{X} 13$ & 5,28 & 6,00 & 6 \\
\hline & $\mathrm{X} 6$ & 5,38 & 5,00 & 6 \\
\hline & X24 & 5,31 & 5,00 & 6 \\
\hline & X9 & 5,19 & 5,00 & 6 \\
\hline & X25 & 5,17 & 5,00 & 5 \\
\hline & $\times 15$ & 5,15 & 5,00 & 5 \\
\hline & $\mathrm{X} 16$ & 5,15 & 5,00 & 5 \\
\hline & $\mathrm{X} 3$ & 5,07 & 5,00 & 5 \\
\hline & $\mathrm{X} 12$ & 5,05 & 5,00 & 5 \\
\hline \multirow{11}{*}{ Nível 2} & $\mathrm{X} 1$ & 4,98 & 5,00 & 5 \\
\hline & $\times 19$ & 4,89 & 5,00 & 5 \\
\hline & $\mathrm{X} 4$ & 4,85 & 5,00 & 4 \\
\hline & $\mathrm{X} 2$ & 4,84 & 5,00 & 5 \\
\hline & $\mathrm{X} 20$ & 4,84 & 5,00 & 5 \\
\hline & $\mathrm{X} 21$ & 4,84 & 5,00 & 5 \\
\hline & $\mathrm{X} 22$ & 4,83 & 5,00 & 5 \\
\hline & $\mathrm{X} 17$ & 4,80 & 5,00 & 5 \\
\hline & $\mathrm{X} 18$ & 4,73 & 5,00 & 5 \\
\hline & $\times 5$ & 4,68 & 5,00 & 5 \\
\hline & $\mathrm{X} 23$ & 4,54 & 5,00 & 4 \\
\hline \multirow{3}{*}{ Nível 3} & $\mathrm{X} 10$ & 4,42 & 4,00 & 4 \\
\hline & $\mathrm{X} 7$ & 4,33 & 4,00 & 4 \\
\hline & $\mathrm{X} 11$ & 4,28 & 4,00 & 4 \\
\hline
\end{tabular}

Nesse quadro, repartimos as variáveis em três níveis, sendo que no primeiro nível a média situa-se entre 5,52 e 5,05, correspondendo às variáveis X14, X8, X13, X6, X24, 
X9, X25, X15, X16, X3 e X12. No segundo nível, a média situa-se entre os valores 4,8 e 4,54, correspondente às variáveis X1, X19, X4, X2, X20, X21, X22, X17, X18, X5 e X23. Por último, no terceiro nível, a média situa-se entre os valores 4,42 e 4,28, correspondente às variáveis $\mathrm{X} 10, \mathrm{X} 7$ e X11.

Analisando a mediana nos diferentes níveis, verificamos que no primeiro nível aparecem os valores de 6,00 e 5,00, no segundo nível ,os valores de 5,00 e no terceiro nível, os valores de 4,00. Relativamente à moda, verificamos que no primeiro nível temos o valor 6 e 5, no segundo nível temos o valor 5 e 4, tendo nesse caso duas variáveis que se desenquadram em termos da moda, que são o X4 e o X23 por apresentarem o valor de 4, e por último, no terceiro nível, temos o valor de 4.

Podemos concluir que a variável X14 (capacidade de mensurar fiavelmente o justo valor) é considerada aquela que provavelmente terá maior influência nas empresas para adoptarem a IAS 41 "Agricultura", seguindo-se por ordem decrescente de importância as variáveis: X8 (decisão da gestão), X13 (confiança nos resultados obtidos com aplicação da IAS), X6 (existência de pessoal qualificado), X24 (acompanhamento das exigências contabilísticas), X9 (estarem teoricamente preparados), X25 (interesse pela inovação), X15 (melhorar os níveis de informação contabilística), X16 (concordância com o reconhecimento em perdas e ganhos dos ajustamentos do justo valor), X3 (facilidade de adaptação a mudanças) e X12 (confiança na aplicabilidade da IAS).

Verificamos que os inquiridos, tendo em conta o valor das medidas calculadas previamente, deram mais relevância às variáveis associadas à aplicabilidade da IAS 41, assim como às variáveis associadas à experiência e conhecimento quer da IAS 41 quer de outras normas, donde podemos concluir que os inquiridos consideraram relevante para o sector a aplicabilidade da IAS.

De seguida, iremos proceder à análise factorial, visto estarmos perante variáveis fortemente correlacionadas, simplificando assim os dados amostrais através da redução do número de variáveis necessárias para explicar a correlação das mesmas.

\subsubsection{Análise Factorial}

A análise factorial pressupõe a existência de um número menor de variáveis não observáveis e subjacentes aos dados que expressam o que existe em comum nas variáveis iniciais.

Para verificar se a análise factorial é adequada, calculámos a estatística de KMO e realizámos o teste de Bartlett (quadro 4). Tendo em conta o valor de $\operatorname{KMO}(0,810)$, e uma vez que o teste de Bartlett tem associado um nível de significância de 0,000, leva-nos à rejeição da hipótese da matriz das correlações na população ser a matriz identidade, mostrando assim que a correlação entre algumas variáveis é estatisticamente significativa. Podemos concluir pela adequabilidade da análise factorial. 
Quadro 4 - Teste KMO e Bartlett

\begin{tabular}{llr}
\hline Kaiser-Meyer-Olkin Measure of Sampling Adequacy. &, 810 \\
\hline Bartlett's Test of Sphericity & Approx. Chi-Square & 2445,227 \\
& df & 300 \\
& Sig. &, 000 \\
\hline
\end{tabular}

No Quadro 5, apresentámos os resultados da análise factorial, utilizando para a extracção dos factores o método das componentes principais. Para efectuar a rotação dos eixos factoriais, utilizámos o método ortogonal Varimax com normalização de Kaiser, cujo objectivo, segundo Maroco (2007), é a obtenção de uma estrutura factorial na qual uma e apenas uma das variáveis originais esteja fortemente associada com um único factor, estando, contudo, pouco associada com os restantes factores.

\section{Quadro 5 - Resultados da Análise Factorial}

\begin{tabular}{|c|c|c|c|c|c|}
\hline \multirow[t]{2}{*}{ Componentes } & \multicolumn{5}{|c|}{ Factores } \\
\hline & Factor 1 & Factor 2 & Factor 3 & Factor 4 & Factor 5 \\
\hline $\mathrm{X} 1$ & & & & 0,561 & \\
\hline $\mathrm{X} 2$ & 0,728 & & & & \\
\hline $\mathrm{X} 3$ & 0,619 & & & & \\
\hline $\mathrm{X} 4$ & & & & & 0,719 \\
\hline$x 5$ & & & & & \\
\hline$x 6$ & 0,827 & & & & \\
\hline $\mathrm{X} 7$ & 0,565 & & & & \\
\hline $\mathrm{x} 8$ & & & & & 0,877 \\
\hline X9 & & & & & 0,562 \\
\hline $\mathrm{X} 10$ & 0,793 & & & & \\
\hline $\mathrm{X} 11$ & 0,688 & & & & \\
\hline $\mathrm{X} 12$ & 0,682 & & & & \\
\hline $\mathrm{X} 13$ & 0,694 & & & & \\
\hline $\mathrm{X} 14$ & & 0,698 & & & \\
\hline X15 & & 0,688 & & & \\
\hline $\mathrm{X} 16$ & & 0,549 & & & \\
\hline $\mathrm{X} 17$ & & & & 0,832 & \\
\hline $\mathrm{X} 18$ & & & & 0,793 & \\
\hline X19 & & 0,896 & & & \\
\hline
\end{tabular}




\begin{tabular}{|c|c|c|c|c|c|} 
X20 & & 0,814 & & \\
X21 & & & 0,758 & & \\
X22 & & & 0,802 & & \\
X23 & & & 0,669 & & \\
X24 & 0,567 & & & & \\
X25 & & & 0,695 & & \\
\hline Variância explicada & 24,77 & 17,66 & 14,27 & 11,96 & 9,75 \\
Variância acumulada & 24,77 & 42,43 & 56,70 & 68,65 & 78,40 \\
Valor próprio & 6,192 & 4,415 & 3,567 & 2,989 & 2,436 \\
Alpha Cronbach's & 0,94 & 0,90 & 0,89 & 0,86 & 0,74 \\
\hline
\end{tabular}

A análise factorial, respeitando o critério da variância explicada, resultou na extracção de cinco factores responsáveis por 78,40\% da variância total (Quadro 5). A variância não explicada, de 21,60\%, poderá estar relacionada com outros factores menos relevantes, resultantes de outras combinações das variáveis. O Alpha de Cronbach indica-nos que estamos perante uma consistência interna muito boa nos factores 1 e 2 (Alpha de Cronbach $=0,94$ e 0,90 respectivamente), uma consistência interna boa nos factores 3 e 4 (Alpha de Cronbach $=0,89$ e 0,86 respectivamente) e uma consistência interna razoável no factor 5 (Alpha de Cronbach $=0,74$ ).

No Quadro 6 descrevemos como foram denominados e interpretados os factores seleccionados a partir da análise das componentes principais.

\section{Quadro 6 - Factores resultantes da análise factorial}

\begin{tabular}{|l|l|c|c|}
\hline \multirow{2}{*}{ Factores } & \multicolumn{1}{|c|}{$\begin{array}{c}\text { Variáveis por ordem decrescente } \\
\text { associadas ao factor }\end{array}$} & Sinal & $\begin{array}{c}\text { Interpretação dos } \\
\text { factores }\end{array}$ \\
\hline \multirow{5}{*}{ Factor $\mathbf{1}$} & - Existência de pessoal qualificado; & + & \\
& - Efectuarem reavaliações livres; & + & \\
& - Experiência na aplicação de outras IAS; & + & \\
& - Confiança nos resultados obtidos com aplicação & + & Preparação para inovação \\
& - Efectuarem reavaliações legais; & + & \\
& - Confiança na aplicabilidade da IAS; & + & \\
& - Facilidade de adaptação a mudanças; & + & \\
& - Acompanhamento das exigências contabilísticas. & + & \\
\hline
\end{tabular}




\begin{tabular}{|c|c|c|c|}
\hline Factor 2 & $\begin{array}{l}\text { - Concorda que a norma só seja aplicada aos pro- } \\
\text { dutos agrícolas no momento da colheita; } \\
\text { - Concorda com a distinção entre subsídios gover- } \\
\text { namentais condicionais e não condicionais; } \\
\text { - Capacidade de mensurar fiavelmente o justo valor; } \\
\text { - Melhorar os níveis de informação contabilística; } \\
\text { - Concordância com o reconhecimento em perdas } \\
\text { e ganhos dos ajustamentos do justo valor. }\end{array}$ & $\begin{array}{l}+ \\
+ \\
+\end{array}$ & $\begin{array}{l}\text { Concordância com aspectos } \\
\text { da norma }\end{array}$ \\
\hline Factor 3 & $\begin{array}{l}\text { - Melhorar a comparação entre as empresas do } \\
\text { sector; } \\
\text { - Melhorar os níveis de informação para a gestão; } \\
\text { - Interesse pela inovação; } \\
\text { - Serem pioneiros dentro do sector. }\end{array}$ & + & $\begin{array}{l}\text { Interesse pela informação no } \\
\text { sector e inovação }\end{array}$ \\
\hline Factor 4 & $\begin{array}{l}\text { - Concordância com a distinção entre activos bio- } \\
\text { lógicos consumíveis e de produção; } \\
\text { - Concordância com a distinção entre activos bioló- } \\
\text { gicos maduros ou adultos e imaturos ou juvenis; } \\
\text { - Conhecimento da IAS } 41 \text {. }\end{array}$ & + & $\begin{array}{l}\text { Conhecimento da norma re- } \\
\text { lativamente à distinção de } \\
\text { activos biológicos }\end{array}$ \\
\hline Factor 5 & $\begin{array}{l}\text { - Decisão da gestão; } \\
\text { - Pertencerem a grupos internacionais; } \\
\text { - Estarem teoricamente preparados. }\end{array}$ & + & Preparação teórica \\
\hline
\end{tabular}

Relativamente ao factor 1, a observação das variáveis que contribuem para explicar esse factor permite-nos concluir que estamos perante as variáveis relacionadas com a inovação, baseando-nos essencialmente: na existência de pessoal qualificado (X6), efectuarem reavaliações livres (X10), experiência na aplicação de outras IAS (X2), confiança nos resultados obtidos com aplicação da IAS (X13), efectuarem reavaliações legais (X11), confiança na aplicabilidade da IAS (X12), facilidade de adaptação a mudanças (X3) e acompanhamento das exigências contabilísticas (X24). Assim, esse factor é explicado pelas empresas que tentam acompanhar as novas exigências contabilísticas, relevando o pessoal qualificado com experiência na aplicação de outras normas internacionais.

Para o factor 2, contribui um conjunto de variáveis relacionadas com aspectos da norma, apoiando a sua aplicação aos produtos agrícolas no momento da colheita (X19), concordando com a distinção entre subsídios governamentais condicionais e não condicionais (X20), confiando na capacidade de mensurar fiavelmente o justo valor (X14), considerando que a norma melhora os níveis de informação contabilística (X15) e concordando com o reconhecimento em perdas e ganhos dos ajustamentos do justo valor (X16).

Por sua vez, as variáveis que contribuem para o factor 3 estão relacionadas com o interesse pela informação no sector e inovação, sendo essa a sua prioridade. Essas variáveis 
relevam a comparação entre empresas do sector (X22), os níveis de informação para a gestão (X21), o interesse pela inovação $(X 25)$ e, por serem pioneiros dentro do sector (X23).

Já no que se refere ao factor 4 , as variáveis que lhe estão associadas revelam conhecimento da norma relativamente à distinção de activos biológicos, por concordarem com a distinção entre activos biológicos consumíveis e de produção (X17), concordarem com a distinção entre activos biológicos maduros ou adultos e imaturos ou juvenis (X18) e, pela importância no conhecimento da IAS 41 (X1).

Por fim, as variáveis associadas ao factor 5 estão relacionadas com a preparação teórica. Assim, para esse factor contribuem as seguintes variáveis: decisão da gestão (X8), pertencerem a grupos internacionais $(X 4)$ e, estarem teoricamente preparados (X9). Julgámos que tanto as decisões da gestão como o facto de pertencerem a grupos internacionais revelam factores de maior abertura a novos conhecimentos.

Resumindo, verificamos que a análise factorial substitui variáveis por factores. Cada factor ao representar um conjunto de variáveis relaciona-se mais com a preparação para a inovação (factor 1), com a concordância com aspectos da norma (factor 2), com o interesse pela informação no sector e inovação (factor 3 ), com o conhecimento da norma relativamente à distinção de activos biológicos (factor 4) ou com a preparação teórica (factor 5). Considerámos que atingiríamos mais facilmente o nosso objectivo de averiguar quais as variáveis que poderão influenciar as empresas a adoptar e utilizar a IAS 41, associando algumas dessas empresas com base nos factores agora determinados. Para isso, vamos proceder à análise de clusters.

\subsection{3 - Análise de Clusters}

Através da análise de clusters, vamos classificar as empresas em grupos ou categorias, de forma a verificar se os factores contribuem para a associação entre as mesmas. Os clusters formam-se com base nos pares de casos mais próximos de acordo com uma medida de distância escolhida, que no nosso caso foi o quadrado da distância Euclideana ${ }^{1}$ , seguindo o método da análise de clusters hierárquica.

Procedemos à análise ${ }^{2}$ do $\mathrm{R}^{2}$ que serve para analisar as diferenças entre cada grupo ou cluster, ou seja, mede a percentagem da variabilidade total que é retida em cada uma das soluções dos clusters. Quando as empresas se concentram num único cluster, a variabilidade entre clusters é zero.

Através da análise de variância univariada, conseguimos testar em simultâneo a igualdade das médias dos 5 factores obtidos na análise factorial nos quatro clusters agora constituídos. Para testar as diferenças entre as médias dos factores nos clusters, procede-

\footnotetext{
1 Quando dois casos são semelhantes, o valor da medida das distâncias é pequeno e o valor da medida das semelhanças é grande, porque enquanto as distâncias medem o afastamento entre dois casos, as semelhanças medem quão perto estão esses casos entre si (PESTANA E GAGEIRO, 2008:558). ${ }^{2} \mathbf{R}^{2}$ - obtém-se através da divisão da soma de quadrados dos clusters de todas as variáveis dependentes pela soma dos quadrados
totais para todas as variáveis, ou seja, R2 = SQC/SQT (MAROCO, 2007).
} 
mos ao teste One-way Anova de forma a detectar factor a factor quais apresentam diferenças nas médias estatisticamente significativas entre os clusters.

No Quadro 7, podemos analisar as medidas de estatística descritiva e o número de elementos em cada cluster. o cluster 1 tem 70 empresas, o cluster 2 tem 6 empresas, o cluster 3 tem 3 empresas e o cluster 4 tem 2 empresas. A média dos quatro primeiros factores é positiva nos clusters 1 e 3 e é negativa nos clusters 2 e 4 (excepção do factor 2). Quanto ao factor 5, verificamos que o cluster que aparece com um valor negativo é o 1 (com média abaixo da média), aparecendo os restantes clusters com valores estandardizados positivos (com média acima de zero).

\section{Quadro 7 - Médias dos factores}

\begin{tabular}{|c|c|c|c|c|c|c|}
\hline \multirow{2}{*}{$\begin{array}{c}\text { Grupos } \\
\text { (Clusters) }\end{array}$} & \multirow{2}{*}{$\begin{array}{c}\mathbf{N}^{\mathbf{0}} \\
\text { Empresas }\end{array}$} & \multicolumn{5}{|c|}{ Médias dos factores } \\
\hline & & Factor 1 & Factor 2 & Factor 3 & Factor 4 & Factor 5 \\
\hline 1 & 70 & 0,0823873 & 0,0896000 & 0,1356640 & 0,0743046 & $-0,0766535$ \\
\hline 2 & 6 & $-0,2703486$ & $-1,7313944$ & $-1,5422572$ & $-1,5372751$ & 0,1426769 \\
\hline 3 & 3 & 1,1431854 & 0,2832940 & 0,4402007 & 1,4475960 & 1,4301745 \\
\hline 4 & 2 & $-3,7872862$ & 1,6332421 & $-0,7817687$ & $-0,1602295$ & 0,1095794 \\
\hline
\end{tabular}

Assim, a análise de clusters efectuada a partir de 5 factores extraídos da análise factorial resultou na extracção de 4 diferentes grupos de empresas relativamente homogéneas. De seguida, vamos interpretar cada um dos grupos encontrados de forma a hierarquizar as variáveis definidas inicialmente. O cluster 1 é constituído por 70 empresas que, por um lado, têm interesse na informação e imagem e, por outro, têm conhecimento da norma, principalmente no que diz respeito à distinção de activos biológicos, considerando que estão preparadas para a inovação. Assim, verificamos uma média positiva no interesse pela informação e imagem (factor 3), na concordância com vários aspectos da norma (factor 2), na preparação para a inovação (factor 1) e no conhecimento da norma relativamente à distinção de activos biológicos (factor 4). Podemos verificar que as empresas que se encontram no cluster 1 registam uma maior média noutros clusters. No entanto, o factor que tem maior média nesse cluster é o factor 3 , pelo que associamos o cluster 1 ao factor 3, como sendo constituído pelas empresas que se interessam pela informação e inovação e como sendo esse cluster o que contém as variáveis consideradas mais relevantes pelos inquiridos, uma vez que associado a esse cluster estão 70 empresas ( $86 \%$ da amostra enquadra-se nesse grupo).

O segundo cluster é constituído por 6 empresas. Tendo em conta a média dos factores, verificamos que nesse cluster encontram-se as empresas teoricamente preparadas (factor 5), por ser o único factor com média positiva. Por sua vez, o cluster 3 é constituído 
por 3 empresas que, apesar de ter média positiva em todos os factores e por alguns desses factores já estarem associados a outros clusters, considerámos que estão associadas às empresas preparadas para inovar (factor 1) e às empresas com conhecimento da norma relativamente à distinção de activos biológicos (factor 4). Apesar do factor 2 ter média positiva nesse cluster e ainda não estar associado a nenhum cluster anterior, não o considerámos como pertencente a esse cluster por ter maior média no cluster 4 . Assim, o cluster 4 é constituído por 2 empresas que concordam com vários aspectos da norma (factor 2). Em termos de síntese, apresentámos no Quadro 8 os resultados da análise de clusters.

\section{Quadro 8 - Resultado da análise de Clusters}

\begin{tabular}{|cccccc|}
\hline & Factor 1 & Factor 2 & Factor 3 & Factor 4 & Factor 5 \\
\hline Cluster 1 & & $\mathrm{X}$ & & \\
Cluster 2 & & & $\mathrm{X}$ & \\
Cluster 3 & $\mathrm{X}$ & $\mathrm{X}$ & & & \\
Cluster 4 & & & & \\
\hline
\end{tabular}

De acordo com Maroco (2007), a análise de clusters é uma técnica multivariada que não possui sólidos fundamentos teóricos, agrupando objectos mais ou menos homogéneos segundo critérios mais ou menos heurísticos. Daí que a análise de clusters deva ser fundamentada com outras análises, com as quais é possível calcular probabilidades de erro associadas às conclusões obtidas. Nesse sentido, para validar a análise de clusters, vamos proceder à análise discriminante.

\subsection{4 - Análise Discriminante}

Segundo Pestana e Gageiro (2008), a análise discriminante tem como objectivo escolher as variáveis que distinguem os grupos para que, conhecendo as características de um novo caso, se possa prever a que grupo pertence. Dessa forma, poder-se-á dizer que consiste em criar funções discriminantes, resultantes de combinações lineares das variáveis iniciais que maximizam as diferenças entre as médias dos grupos e minimizam as probabilidades de classificações incorrectas dos casos nos grupos.

Essa análise permite-nos validar a análise de clusters e simultaneamente confirmar os resultados da análise factorial. Assim, por meio do Quadro 9, verificamos que a primeira função discriminante contribui com $67,5 \%$ do total da variância entre os grupos, sendo a que tem maior poder de separação. A segunda explica $20,5 \%$ da variância intergrupal que conjuntamente com a primeira conseguem diferenciar os grupos substancialmente. A terceira função apenas explica $11,9 \%$ da variância intergrupal. 


\section{Quadro 9 - Valores Próprios}

\begin{tabular}{|c|c|c|c|c|}
\hline Função & Valor Próprio & \% da Variância & \% Acumulada & $\begin{array}{c}\text { Correlação } \\
\text { Canónica }\end{array}$ \\
\hline 1 & $8,490(a)$ & 67,5 & 67,5 &, 946 \\
\hline 2 & $2,583(a)$ & 20,5 & 88,1 &, 849 \\
\hline 3 & $1,497(a)$ & 11,9 & 100,0 &, 774 \\
\hline
\end{tabular}

a) As primeiras 3 funções discriminantes canónicas foram usadas na análise.

Para avaliar a partir de que valor a percentagem de casos correctamente classificada é aceitável, vamos comparar as classificações correctas com os resultados de uma classificação obtida ao acaso, conforme Quadro 10. De acordo com Pestana e Gageiro (2008, p. 668), calculámos em cada grupo a probabilidade a priori (ni/N) e a percentagem de casos classificados correctamente pelo acaso, obtidas pelo produto da probabilidade a priori com o número de elementos de cada grupo (ni). A soma dessa classificação $(60,8)$ divide-se pelo total de elementos (81), obtendo-se a percentagem de classificações correctas de $75,1 \%$ dadas pelo acaso.

\section{Quadro 10 - Classificações Correctas Feitas ao Acaso}

\begin{tabular}{|l|c|c|c|c|c|}
\hline & Clu1 & Clu2 & Clu3 & Clu4 & Total \\
\hline $\mathrm{N}$ & 70 & 6 & 3 & 2 & 81 \\
\hline Prioridade a priori & $\mathbf{0 , 8 6}$ & 0,07 & 0,04 & 0,03 & 1 \\
\hline Classificações correctas & 60,2 & 0,42 & 0,12 & 0,06 & 60,8 \\
\hline
\end{tabular}

Como as classificações correctas têm que ser superiores ao maior valor entre a máxima probabilidade a priori e a percentagem de classificações correctas obtidas ao acaso, e no nosso estudo temos $100 \%>(\operatorname{Max}\{86,0 \% ; 75,1 \%\}=86,0 \%)$, o que revela a quase perfeita classificação de casos, validando assim os resultados da análise de clusters.

Validada a análise de clusters, interessa agora caracterizar as empresas de cada grupo. Assim, verificamos que o cluster 1 é constituído pelas empresas que dão mais importância ao conjunto de variáveis empenhadas em melhorar a comparação entre as empresas do sector e os níveis de informação para a gestão, têm interesse pela inovação e são pioneiras dentro do sector.

O cluster 2 é constituído pelas empresas que dão mais importância às variáveis associadas à preparação teórica, por darem relevância à decisão da gestão, pertencem a grupos internacionais e estão teoricamente preparadas. 
O cluster 3 engloba as empresas que dão importância às variáveis relacionadas com a preparação para a inovação e às variáveis relacionadas com o reconhecimento da norma relativamente à distinção de activos biológicos. Assim, essas empresas dão relevância à existência de pessoal qualificado, ao facto de efectuarem reavaliações livres, à experiência na aplicação de outras IAS, à confiança nos resultados obtidos com aplicação da IAS, ao facto de efectuarem reavaliações legais, à confiança na aplicabilidade da IAS, à facilidade de adaptação a mudanças e ao acompanhamento das exigências contabilísticas. Conjugadas com essas variáveis, as empresas pertencentes a esse cluster, tendo conhecimento da IAS 41, também concordam com a distinção entre activos biológicos consumíveis e de produção, com a distinção entre activos biológicos maduros ou adultos e imaturos ou juvenis.

Por último, o cluster 4 é constituído pelas empresas que concordam com vários aspectos da norma. Assim, concordam que a norma só seja aplicada aos produtos agrícolas no momento da colheita, com a distinção entre subsídios governamentais condicionais e não condicionais, com a capacidade de mensurar fiavelmente o justo valor, com o reconhecimento em perdas e ganhos dos ajustamentos do justo valor e, com o facto dessa informação melhorar os níveis de informação contabilística.

Interessa ainda salientar que a maioria das empresas se encontra no cluster 1 por estarmos perante empresas de pequena ou média dimensão, como é o nosso caso e em geral o caso português, pelo que essas empresas dão relevância à comparação entre as empresas no sector e até por serem pioneiras no mesmo (características do cluster 1).

\section{CONCLUSÕES}

A tendência actual para a utilização do justo valor tem servido de base para muitas controvérsias e polémicas por ser um tema pouco consensual, a começar logo pela sua própria definição.

Toda a polémica levantada conduziu a uma maior relevância da valorização do justo valor em relação ao custo histórico, ainda que isso possa levar, pelo menos numa primeira fase, a alguma redução da fiabilidade e ao aumento da complexidade do sistema devido à própria aceitabilidade da valorização do justo valor. Tendo o justo valor suscitado a atenção e o interesse por parte dos organismos internacionais, levando à publicação de uma norma internacional de contabilidade sobre agricultura (IAS 41) e em nível Nacional a NCRF 17 "Agricultura", salientamos alguns pontos polémicos dos quais podemos concluir que o justo valor pode ser determinado com base no preço de mercado activo quando ele existir, considerando-se essa a mensuração mais fiável para esse activo. No caso do sector vitivinícola, temos consciência de que é difícil encontrarmos mercado activo devido às características das videiras e das respectivas uvas nas diferentes regiões, contudo consideramos adequada a opção da CNC na aceitação do Sistema de Informação de Mercado Agrícola (SIMA) para determinação do valor de mercado. 
Consideramos que os rendimentos não realizados influenciam erradamente os resultados, quer por meio dos indicadores de desempenho da empresa quer por meio dos sócios/accionistas, acerca do valor a distribuir como dividendos. Entendemos que as variações resultantes do justo valor relativas ao valor das videiras podem estar condicionadas, por exemplo, pelas condições climatéricas, o que por sua vez vai influenciar o resultado. Assim, e apesar da própria CNC também considerar, tal como as normas em nível internacional, que as variações do justo valor devem ser levadas para resultados do período a que dizem respeito, consideramos adequado que, para salvaguardar os resultados não realizados, os mesmos não sejam distribuídos ou sirvam para aumentos do capital social.

Relativamente ao estudo empírico realizado e tendo em conta as limitações da investigação, até por se tratar de uma amostra por conveniência, inferimos que os resultados obtidos na análise descritiva deram mais relevância às variáveis relacionadas com a aplicabilidade, a experiência e o conhecimento da norma e de outras normas, ou seja, consideram a aplicabilidade da norma relevante para o sector.

Agrupando as variáveis iniciais relacionadas com a adopção e a utilização da IAS 41 , obtivemos 5 factores ou grupos responsáveis por $78 \%$ da variância acumulada, sendo que o primeiro factor compreende o grupo de variáveis relacionadas com a preparação para a inovação, o segundo grupo compreende as variáveis relacionadas com a concordância com vários aspectos da norma, o terceiro grupo é composto pelas variáveis que revelam interesse pela informação e imagem, o quarto grupo compreende as variáveis relacionadas com o conhecimento da norma relativamente à distinção de activos biológicos e, por fim, o quinto grupo é constituído pelas variáveis que revelam preparação teórica.

Depois de analisada a existência, ou não, de associação dos factores, concluímos que o primeiro e o quarto factores estão associados, pelo que ficam agrupados apenas num único cluster, desse facto resultam, assim, 4 clusters. O primeiro cluster é constituído por 70 empresas, tendo estas interesse pela informação e pela imagem. O segundo cluster é constituído por 6 empresas, as quais estão teoricamente preparadas, dando relevância à decisão da gestão e ao facto de pertencerem a grupos internacionais. O terceiro cluster é constituído por 3 empresas que estão preparadas para a inovação e que têm conhecimento da norma relativamente à distinção de activos biológicos. O quarto e último cluster é constituído por 2 empresas que confiam na norma. Assim, podemos concluir que temos quatro grupos de empresas dando relevância a variáveis diferentes relativamente ao objectivo do nosso estudo.

\section{BIBLIOGRAFIA}

ABE, R. Comments on E65, "Agriculture". In: International Accounting Standards Board. University of Kyoto - Japan, 2000. Disponível em: <http://www.iasb.org.uk>. Acesso em 30 Dezembro 05. 
AMEN, M. Comments on E65, "Agriculture". In: International Accounting Standards Board. University of Berne - Switzerland, 2000. Disponível em: <http://www.iasb.org.uk>. Acesso em 30 Dezembro 05.

AMERICAN INSTITUTE OF CERTIFIED PUBLIC ACCOUNTANTS (AICPA), Comments on E65, "Agriculture". In: International Accounting Standards Board, 2000. Disponível em: $<$ http://www.iasb.org.uk>. Acesso em 30 Dezembro 05.

ASCOM. Comments on E65, "Agriculture". In: International Accounting Standards Board. Switzerland, 2000. Disponível em: <http://www.iasb.org.uk>. Acesso em 30 Dezembro 05.

ASSOCIATION OF CHARTERED CERTIFIED ACCOUNTANTS (ACCA). Comments on E65, "Agriculture". In: International Accounting Standards Board. UK, 2000. Disponível em: <http://www.iasb.org.uk>. Acesso em 30 Dezembro 05.

AUSTRALASIAN COUNCIL OF AUDITORS-GENERAL (ACAG). Comments on E65, "Agriculture". In: International Accounting Standards Board. Australia, 2000. Disponivel em: $<$ http://www.iasb.org.uk>. Acesso em 30 Dezembro 05.

BARROS, A. J. P.; LEHFELD, N. A. S. Fundamentos de Metodologia: Um Guia para a Iniciação Científica. São Paulo: Mc Graw-Hill, 1986.

CAIRNS, D.; MASSOUDI, D.; TAPLIN, R.; TARCA, A. IFRS Fair Value Measurement and Accounting Policy Choice in the United Kingdom and Australia. February 6, 2009. AAA 2009 Mid-Year International Accounting Section (IAS) Meeting. Disponível em: SSRN: <http:// ssrn.com/abstract $=1274024>$.

COMISSÃO EUROPEIA (CE). Regulamento n. ${ }^{\circ} 1606 / 2002$ do Parlamento Europeu e do Conselho. Jornal Oficial das Comunidades Europeias. 2002. Disponível em: <http:// www.cnc.min-financas.pt>. Acesso em 14 Outubro 07.

COMISSÃO DE NORMALIZAÇÃO CONTABILÍSTICA (CNC). Projecto de Linhas de Orientação Para Um Novo Modelo de Normalização Contabilística. Aprovado pelo Conselho Geral da CNC na sua reunião de 15 de Janeiro de 2003.

CONSIGLIO NAZIONALE DEI DOTTORI COMMERCIALISTI (CNDC); CONSIGLIO NAZIONALE DEI RAGIONIERI (CNR) -2000. Comments on E65, "Agriculture". In: International Accounting Standards Board. Joint Response, Italy, 2000. Disponível em: <http:// www.iasb.org.uk>. Acesso em 30 Dezembro 05. 
DELOITTE TOUCHE TOHMATSU, International. Comments on E65, "Agriculture". In: International Accounting Standards Board, 2000. Disponivel em: <http://www.iasb.org.uk>. Acesso em 30 Dezembro 05.

EAST AFRICAN COFFE PLANTATIONS (EACP). Comments on E65, "Agriculture". In: International Accounting Standards Board. Australia, 2000. Disponível em: <http://www. iasb.org.uk>. Acesso em 30 Dezembro 05.

EASTERN PRODUCE KENYA (EPK). Comments on E65, "Agriculture". In: International Accounting Standards Board, 2000. Disponível em: <http://www.iasb.org.uk >. Acesso em 30 Dezembro 05.

ELAD, C. Fair Value Accounting and Fair Trade: an Analysis of the Role of International Accounting Atandard $n^{\circ}$ 41. In: Social Conflit. Socio-Economic Review, Vol. 5, No 4, p. 755-777, 2007.

. Fair Value Accounting in the Agricultural Sector: Some Implications for International Accounting Harmonization. In: European Accounting Review, Vol. 13, № 4, 2004.

ERNST \& YOUNG - International. Comments on E65, "Agriculture". In: International Accounting Standards Board, 2000. Disponível em: <http://www.iasb.org.uk>. Acesso em 30 Dezembro 05.

F HOFFMANN-LA ROCHE. Comments on E65, "Agriculture". In: International Accounting Standards Board. Switzerland, 2000. Disponível em: <http://www.iasb.org.uk>. Acesso em 30 Dezembro 05.

FEDERATION OF SWISS INDUSTRIAL HOLDING COMPANIES (FSIHC). Comments on E65, "Agriculture". In: International Accounting Standards Board, 2000. Disponível em: $<$ http://www.iasb.org.uk>. Acesso em 30 Dezembro 05.

FERNANDES, C. G. NIC 41 "Agricultura": Contributos e Constrangimentos para a Imagem Verdadeira e Apropriada na Realidade Portuguesa. Dissertação apresentada à Universidade de Aveiro para obtenção do grau de mestre em Contabilidade e Auditoria, 2009.

FERREIRA, P. L. Estatística Multivariada Aplicada. Caderno de apoio. Faculdade de Economia, Universidade de Coimbra. 2000. 
FÖRENINGEN AUKTORISERADE REVISORER (FAR). Comments on E65, "Agriculture". In: International Accounting Standards Board. Sweden, 2000. Disponível em: <http:// www.iasb.org.uk>. Acesso em 30 Dezembro 05.

FIJI INSTITUTE OF ACCOUNTANTS (FIA). Comments on E65, “Agriculture”. In: International Accounting Standards Board, 2000. Disponível em: <http://www.iasb.org.uk>. Acesso em 30 Dezembro 05.

GABINETE DE PLANEAMENTO E POLÍTICAS (GPP). Sistema de Informação de Mercados Agrícolas (SIMA), (Online) Disponível em: <http://www.gpp.pt/sima.html>. Acesso em Agosto 2009.

GROUP OF 100 (G100). Comments on E65, “Agriculture”. In: International Accounting Standards Board, 2000. Disponível em: <http://www.iasb.org.uk>. Acesso em 30 Dezembro 05.

HAIR, J. F.; ANDERSON, R. E.; TATHAM, R. L.; BLACK, W. C. Multivariate Data Analysis with Readings. Fourth Edition, Englewood Cliffs, New Jersey, 1995.

HILL, M.M.; HILL, A. Investigação por Questionário. 2. ed. rev. e cor., Lisboa: Edições Sílabo, Abril 2002.

ILLOVO SUGAR. Comments on E65, "Agriculture". In: International Accounting Standards Board. South Africa, 2000. Disponível em: <http://www.iasb.org.uk>. Acesso em 30 Dezembro 05.

INDIAN INSTITUTE OF MANAGEMENT CALCUTTA (IIMC). Comments on E65, "Agriculture". In: International Accounting Standards Board. India, 2000. Disponível em: <http:// www.iasb.org.uk>. Acesso em 30 Dezembro 05.

INSTITUT DER WIRTSCHAFTSPRÜFER (IDW). Comments on E65, “Agriculture”. In: International Accounting Standards Board. Germany, 2000. Disponível em: <http://www.iasb. org.uk>. Acesso em 30 Dezembro 05.

INSTITUTE OF CERTIFIED PUBLIC ACCOUNTANTS OF KENYA (ICPAK). Comments on E65, “Agriculture”. In: International Accounting Standards Board, 2000. Disponível em: <http://www.iasb.org.uk>. Acesso em 30 Dezembro 05.

INSTITUTE OF CHARTERED ACCOUNTANTS OF ZIMBABWE (ICAZ). Comments on E65, "Agriculture”. In: International Accounting Standards Board, 2000. Disponível em: <http://www.iasb.org.uk>. Acesso em 30 Dezembro 05. 
INSTITUTE OF COST AND MANAGEMENT ACCOUNTANTS OF PAKISTAN (ICMAP). Comments on E65, "Agriculture". In: International Accounting Standards Board, 1999. Disponível em: <http://www.iasb.org.uk>. Acesso em 30 Dezembro 05.

INSTITUTE OF MANAGEMENT ACCOUNTANTS (IMA). Comments on E65, "Agriculture”. In: International Accounting Standards Board. USA, 2000. Disponível em: <http://www.iasb. org.uk>. Acesso em 30 Dezembro 05.

INSTITUTO DE AUDITORES-CENSORES JURADOS DE CUENTAS DE ESPAÑA (IACJCE) - Spain. Comments on E65, "Agriculture", In: International Accounting Standards Board, 2000. Disponível em: <http://www.iasb.org.uk>. Acesso em 30 Dezembro 05.

INTERNATIONAL ACCOUNTING STANDARDS COMMITTEE (IASC). Proposed International Accounting Standard Agriculture. Exposure Draft E65, “Agriculture”, London: IASC, jul. 1999.

International Accounting Standard, IAS 41, "Agriculture”, December, London, 2000. Tradução Portuguesa publicada pela Ordem dos Revisores Oficiais de Contas, com a permissão do IASCF, 2003.

INTERNATIONAL ACTUARIAL ASSOCIATION (IAA). Comments on E65, "Agriculture". In: International Accounting Standards Board, 2000. Disponível em: <http://www.iasb.org. uk>. Acesso em 30 Dezembro 05.

INTERNATIONAL ASSOCIATION OF FINANCIAL EXECUTIVES INSTITUTES (IAFEI). Comments on E65, "Agriculture". In: International Accounting Standards Board, 2000. Disponível em: <http://www.iasb.org.uk>. Acesso em 30 Dezembro 05.

JAPANESE INSTITUTE OF CERTIFIED PUBLIC ACCOUNTANTS (JICPA). Comments on E65, “Agriculture”. In: International Accounting Standards Board, 2000. Disponível em: <http://www.iasb.org.uk>. Acesso em 30 Dezembro 05.

JOHNS N.; LEE-ROSS, D. Research Methods in Service Industry Management, London and New York: CASSELL, 1998.

LESSARD-HÉBERT, M.; GOYETTE, G.; BOUTIN, G. Investigação Qualitativa: Fundamentos e Práticas. Epistemologia e Sociedade, Lisboa: Instituto Piaget, 2005.

MAROCO, J. Análise Estatística - com utilização do SPSS. 3. ed., Lisboa: Edições Sílabo, 2007. 
NATIONAL BOARD OF ACCOUNTANTS AND AUDITORS (NBAA). Comments on E65, "Agriculture". In: International Accounting Standards Board. Tanzania, 2000. Disponível em: <http://www.iasb.org.uk>. Acesso em 30 Dezembro 05.

NESTLÉ. Comments on E65, "Agriculture”. In: International Accounting Standards Board. Swetzerland, 2000. Disponível em: <http://www.iasb.org.uk>. Acesso em 30 Dezembro 05.

NUTRECO. Comments on E65, "Agriculture”. In: International Accounting Standards Board. Netherlands, 2000. Disponível em: <http://www.iasb.org.uk>. Acesso em 30 Dezembro 05.

ORGANIZAÇÃO PARA A COOPERAÇÃO E DESENVOLVIMENTO ECONÓMICO (OCDE). L'OCDE en Chiffres, Statistiques sur Les Pays Membres, L’Observateur. Edition de 2005.

ORGANIZAÇÃO PARA A COOPERAÇÃO E DESENVOLVIMENTO ECONÓMICO; FOOD AND AGRICULTURE ORGANIZATION (OCDE e FAO), Perspectives Agricoles de L'OCDE et de la FAO - 2007-2016, Paris: Éditions OCDE, 2007.

ORDEM DOS REVISORES OFICIAIS DE CONTAS (OROC). Comments on E65, "Agriculture". In: International Accounting Standards Board, 2000. Disponível em: <http://www. iasb.org.uk>. Acesso em 30 Dezembro 05.

PENG, S.; BEWLEY, K. Adaptability of Fair Value Accounting in China: Assessment of an Emerging Economy Converging with IFRS, CAAAAnnual Conference, 2009. Disponível em: $<$ http://ssrn.com/abstract=1326004>.

PESTANA, M. H.; GAGEIRO, J. N. Análise de Dados para Ciências Sociais: A Complementaridade do SPSS., 5. ed. rev. e aum., Lisboa: Sílabo, 2008.

RAAD VOOR DE JAARVERSLAGGEVING, (RJ). Comments on E65, "Agriculture". In: International Accounting Standards Board. Council for Annual Reporting, Netherlands, 2000. Disponível em: <http://www.iasb.org.uk>. Acesso em 30 Dezembro 05.

SOUTH AFRICAN INSTITUTE OF CHARTERED ACCOUNTANTS (SAICA). Comments on E65, "Agriculture". In: International Accounting Standards Board, 2000. Disponível em: <http://www.iasb.org.uk>. Acesso em 30 Dezembro 05.

SULZER - Switzerland. Comments on E65, "Agriculture". In: International Accounting Standards Board, 2000. Disponível em: <http://www.iasb.org.uk>. Acesso em 30 Dezembro 05. 


\section{ANEXO}

\section{CARACTERIZAÇÃO DA EMPRESA}

Relativamente às seguintes questões, assinale com um $X$ as respostas onde se enquadra a sua empresa:

1.1. Natureza Jurídica da Empresa (assinalar com $\mathrm{x}$ ):

Sociedade em Nome Colectivo

Sociedade Unipessoal

Sociedade por Quotas

Sociedade Anónima

Outra

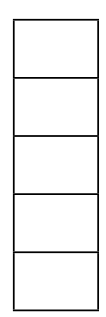

1.2. Capital Social da Empresa (assinalar com $x$ ):

Igual a 0 Euros

De [1- 5.000] Euros

De [5.001-25.000] Euros

De [25.001-50.000] Euros

De [50.001 - 100.000] Euros

De [100.001 - 500.000] Euros

De [500.001 - 1.500.000] Euros

De [1.500.001 - 5.000.000] Euros

De [5.000.001 - 20.000.000] Euros

De [20.000.001-50.000.000] Euros

Superior a 50.000.000 Euros

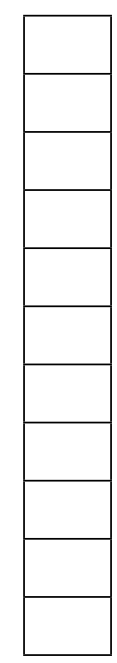

\section{O SECTOR}

Na sua opinião, qual o peso que cada um dos seguintes aspectos poderá ter na adopção e utilização da NIC 41 (faça um círculo no número correspondente):

\begin{tabular}{|l|c|c|c|c|c|c|c|}
\hline & \multicolumn{3}{|c|}{$\begin{array}{c}\text { Pouco } \\
\text { importante }\end{array}$} & \multicolumn{2}{c|}{ Indiferente } & \multicolumn{3}{c|}{$\begin{array}{c}\text { Muito } \\
\text { importante }\end{array}$} \\
\hline Conhecimento da NIC 41 & 1 & 2 & 3 & 4 & 5 & 6 & 7 \\
\hline Experiência na aplicação de outras NIC's & 1 & 2 & 3 & 4 & 5 & 6 & 7 \\
\hline Facilidade de adaptação a mudanças & 1 & 2 & 3 & 4 & 5 & 6 & 7 \\
\hline Pertencerem a grupos internacionais & 1 & 2 & 3 & 4 & 5 & 6 & 7 \\
\hline
\end{tabular}




\begin{tabular}{|c|c|c|c|c|c|c|c|}
\hline Serem vistos como "exemplo" dentro do sector & 1 & 2 & 3 & 4 & 5 & 6 & 7 \\
\hline Existência de pessoal qualificado & 1 & 2 & 3 & 4 & 5 & 6 & 7 \\
\hline Os concorrentes já o terem feito & 1 & 2 & 3 & 4 & 5 & 6 & 7 \\
\hline Decisão da gestão & 1 & 2 & 3 & 4 & 5 & 6 & 7 \\
\hline Estarem teoricamente preparados & 1 & 2 & 3 & 4 & 5 & 6 & 7 \\
\hline Efectuarem reavaliações livres & 1 & 2 & 3 & 4 & 5 & 6 & 7 \\
\hline Efectuarem reavaliações legais & 1 & 2 & 3 & 4 & 5 & 6 & 7 \\
\hline Confiança na aplicabilidade da NIC & 1 & 2 & 3 & 4 & 5 & 6 & 7 \\
\hline Confiança nos resultados obtidos com aplicação da NIC & 1 & 2 & 3 & 4 & 5 & 6 & 7 \\
\hline Capacidade de mensurar fiavelmente o justo valor & 1 & 2 & 3 & 4 & 5 & 6 & 7 \\
\hline Melhorar os níveis de informação contabilística & 1 & 2 & 3 & 4 & 5 & 6 & 7 \\
\hline $\begin{array}{l}\text { Concordância com o conhecimento em perdas e ganhos dos } \\
\text { ajustamentos do justo valor }\end{array}$ & 1 & 2 & 3 & 4 & 5 & 6 & 7 \\
\hline $\begin{array}{l}\text { Concordância com a distinção entre activos biológicos } \\
\text { consumíveis e de produção }\end{array}$ & 1 & 2 & 3 & 4 & 5 & 6 & 7 \\
\hline $\begin{array}{l}\text { Concordância com a distinção entre activos biológicos maduros } \\
\text { ou adultos e imaturos ou juvenis }\end{array}$ & 1 & 2 & 3 & 4 & 5 & 6 & 7 \\
\hline $\begin{array}{l}\text { Concorda que a norma só seja aplicada aos produtos agrícolas } \\
\text { no momento da colheita }\end{array}$ & 1 & 2 & 3 & 4 & 5 & 6 & 7 \\
\hline $\begin{array}{l}\text { Concorda com a distinção entre subsídios governamentais } \\
\text { condicionais e não condicionais }\end{array}$ & 1 & 2 & 3 & 4 & 5 & 6 & 7 \\
\hline Melhorar os níveis de informação para a gestão & 1 & 2 & 3 & 4 & 5 & 6 & 7 \\
\hline Melhorar a comparação entre as empresas do sector & 1 & 2 & 3 & 4 & 5 & 6 & 7 \\
\hline Serem pioneiros dentro do sector & 1 & 2 & 3 & 4 & 5 & 6 & 7 \\
\hline Acompanhamento das exigências contabilísticas & 1 & 2 & 3 & 4 & 5 & 6 & 7 \\
\hline Interesse pela inovação & 1 & 2 & 3 & 4 & 5 & 6 & 7 \\
\hline
\end{tabular}

\section{Muito obrigado pela sua colaboração}

NOTA: Pode consultar as Normas Internacionais de Contabilidade (em Português) no seguinte site: http:// europa.eu.int/eur-lex/pri/pt/oj/dat/2003/I_261/l_26120031013pt00010420.pdf

OBS: Se desejar receber o relatório dos resultados deste trabalho, junte por favor, o seu cartão aquando da devolução deste inquérito ou, em alternativa, indique a morada para onde pretende que seja enviado. 